\title{
Beslenme desteğine yeni başlanan hastaları nazogastrik sondayla taburcu etmek uygun bir yaklaşım mı?
}

\author{
Is it an appropriate approach to discharge patients, newly being fed, via the nasogastric tube?
}

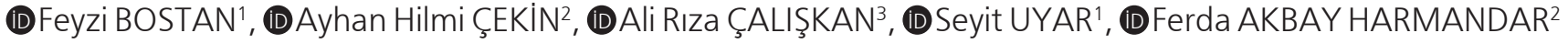 \\ Sağlık Bilimleri Üniversitesi, Antalya Eğitim ve Araştırma Hastanesi ${ }^{1}$ Dahiliye Kliniği, ${ }^{2}$ Gastroenteroloji Kliniği, Antalya \\ İnönü Üniversitesi Tıp Fakültesi, ${ }^{3}$ Gastroenteroloji Bilim Dalı, Malatya
}

\begin{abstract}
Giriş ve Amaç: Başta geriatri, nöroloji ve onkoloji hasta gruplarında olmak üzere çeşitli nedenlerle oral yoldan beslenemeyen hastalar, nazogastrik sonda, perkütan endoskopik gastrostomi ve perkütan endoskopik jejunostomi gibi yapay yollarla enteral yoldan beslenmektedirler. Genel uygulama, hastaların nazogastrik sondayla beslenmeye başlanıp, daha sonra kalıc beslenme yolları olan perkütan endoskopik gastrostomi veya jejunostomiye değiştirilmesi şeklindedir. Kalıc beslenme yollarına geçilmesi zamanlaması konusunda kılavuzlar olmasına rağmen, bu konuda kafa karısıkığı vardır. Biz bu çalışmamızda 6 aylık zaman dilimi içerisinde nazogastrik sonda ile beslenmeye başlanarak taburcu edilen 61 hastayı beslenme yolu değişiklikleri açııından değerlendirmeyi amaçladık. Gereç ve Yöntem: Antalya Eğitim ve Araştırma Hastanesinde Haziran 2015-Aralık 2015 zaman dilimi içerisinde iç hastalıkları kliniği, tıbbi onkoloji kliniği, nöroloji kliniklerinde yatan, altta yatan hastalıkları nedeniyle oral yoldan beslenemeyen ve nütrisyon ekibi tarafından nazogastrik sonda ile beslenmeye başlanıp, nazogastrik tüp ile taburcu edilen 61 hasta ardışık sırayla çalışmaya dahil edildi. Bulgular: Çalışmaya aldığımı hastaların 35'i (\%57.4) erkek, 25'i (\%42.6) kadındı. Çalışma zaman dilimi sonunda 20 (\%41.6) hasta exitus oldu. 12 (19.7) hastaya perkütan endoskopik gastrostomi açıldı. 16 (\%26.2) hasta nazogastrik sondadan ayrılarak oral yoldan beslenmeye başladı. 13 (\%21.3) hasta nazogastrik sondayla beslenmeye devam ediyordu. Hastalarda nazogastrik sonda kalış süresi ortalama $34.93 \pm 40.98$ gün, medyan 30.0 gün (min: 2 gün, max: 180 gün, aralık: 178 gün) olarak saptandı. Sonuç: Takip edilen 61 hastanın sadece 12 (19.7\%) tanesine perkütan endoskopik gastrostomi açılmış olması, bunun yanında hastaların 16'sının (26.2\%) oral yoldan beslenmeye geçmiş olması hastaların nazogastrik sondayla taburcu edilip beslenme yolu değişikliklerine takipte karar verilmesinin doğru bir yaklaşım olduğu kanatine varmamıza neden oldu.
\end{abstract}

Anahtar kelimeler: Nazogastrik sonda, enteral beslenme, perkütan endoskopik gastrostomi

\section{GíRIŞ ve AMAÇ}

Klinik pratikte özellikle nöroloji, geriatri ve onkoloji hasta gruplarında oral yoldan beslenememe sık karşılaşılan sorunlardan birisidir. Bu hasta gruplarında altta yatan hastalığın progresyonu ve/veya araya giren akut bir patoloji (diyare, idrar yolu enfeksiyonu, akut alt solunum yolu enfeksiyonu, akut serebrovasküler hastalık vs.) oral yol-
Background and Aims: Patients who cannot be fed orally due to various reasons, especially those comprising the geriatric, neurological, and oncological patient groups, are fed enterally via artificial routes such as nasogastric tube, percutaneous endoscopic gastrostomy, and percutaneous endoscopic jejunostomy. The general practice is to begin feeding via the nasogastric tube and then replace with permanent feeding routes such as percutaneous endoscopic gastrostomy or jejunostomy. Although guidelines regarding the timing of placing permanent feeding routes are available, confusion still exists in this regard. We conducted this study to evaluate feeding route changes among patients who were discharged by feeding via the nasogastric tube during a 6-month time period. Materials and Method: A total of 61 patients who were hospitalized in the internal medicine clinic, the medical oncology clinic, and the neurology clinic in Antalya Training and Research Hospital from June 2015 to December 2015 were enrolled consecutively in this study. These patients could not be fed via the oral route due to their underlying diseases and were fed via the nasogastric tube by the nutritional team and then discharged with the nasogastric tube feeding route. Results: Of the 61 patients, 35 (57.4\%) were males and 25 (42.6\%) were females. At the end of the study period, 20 patients (41.6\%) died. A total of 12 (19.7) patients were fed with the percutaneous endoscopic gastrostomy route, and 16 (26.2\%) patients restarted feeding via the oral route. Nasogastric tube feeding was continued for 13 (21.3\%) patients. The duration of nasogastric tube feeding was $34.93 \pm 40.98$ days [median 30.0 days (min: 2 days, max: 180 days, range: 178 days)]. Conclusion: Of the 61 patients who were evaluated in this study, 12 (19.7\%) were fed via the percutaneous endoscopic gastrostomy route, whereas 16 (26.2\%) patients restarted feeding via the oral route. This result suggests that the decision to discharge patients with feeding via the nasogastric tube is an appropriate approach.

Key words: Nasogastric tube, enteral feeding, percutaneous endoscopic gastrostomy

dan beslenmeyi tamamen engelleyebilmektedir. Bu grup hastalar nazogastrik/nazoenterik (NG/NE) sondalarla veya girişimsel olarak açılacak perkütan endoskopik gastrostomi (PEG), perkütan endoskopik jejunostomi (PEJ) ile beslenirler (1). Klinik pratikteki uygulama, nütrisyon ekibinin var olduğu ve bu tip hastaların beslenmelerinin

\footnotetext{
Iletişim: Feyzi BOSTAN

Sağlık Bilimleri Üniversitesi, Antalya Eğitim ve Araştırma Hastanesi Dahiliye Kliniği, Varlık Mah., Muratpaşa, Antalya

Tel: +90 2422494400 0-3420 • E-mail: E-mail: feyzi@dr.com
}

Geliş Tarihi: 02.10.2018 • Kabul Tarihi: 10.10.2018

DOI: 10.17941/agd.619163 
bu ekip tarafından yönlendirildiği hastanelerde hastaların NG sondayla beslenmeye başlanıp, akut patolojik durum geçince ya da kronik patolojisinin kliniği yerleşince hastalara PEG/PEJ açılması şeklindedir. Beslenme kılavuzları 6 haftadan uzun süre enteral yoldan beslenmeye devam edilecek hastalara PEG açılmasını önermektedir (2,3). Ancak klinik pratik uygulamalarda hastaya ne zaman PEG açılacağı konusunda kafa karışıklığı vardır.

Hastanemizde tüm kliniklerdeki yatan hastaların nütrisyon durumları rutin olarak ilgili klinik hemşireleri tarafından değerlendirilmekte ve sonuçlar nütrisyon ekibi ile paylaşılmaktadır. Nütrisyon desteğine ihtiyacı olan ve bu ihtiyacı enteral yoldan karşılanmasına karar verilen hastalar NG sondayla beslenmeye başlanıp, hasta yakınlarına NG sondayla besleme konusunda eğitim verildikten sonra taburculukları da NG sondayla yapılmaktadır. Hastaların beslenme yolu değişiklikleri ayaktan takiplerinde karar verilmektedir. Bu çalışmamızda PEG açılması önerilen ve PEG açılana kadar nütrisyon ekibi tarafından NG sondayla taburcu edilen hastaların prospektif olarak takipleri yapımış, beslenme yolu değişiklikleri açısından değerlendirilmiştir

\section{GEREÇ ve YÖNTEM}

Antalya Eğitim ve Araştırma Hastanesinde Haziran 2015 Aralık 2015 zaman dilimi içerisinde iç hastalıkları kliniği, tıbbi onkoloji kliniği, nöroloji kliniklerinde yatan, altta yatan hastalıkları nedeniyle oral yoldan beslenemeyip PEG önerilen, PEG açllana kadar da nütrisyon ekibi tarafından NG sonda ile taburcu edilen 61 hasta ardışık sırayla çaIışmaya dahil edildi. Hastalar bir hekim tarafından haftada bir NG sondaya ait bir komplikasyon olup olmaması açısından telefonla arandı. 2 haftada bir de hastaneye çağırılarak nütrisyon ekibi tarafından hem beslenme durumu açısından hem de yeniden oral yoldan beslenebilme açısından değerlendirildi. Çalışmada Helsinki Bidirgesine uyulmuştur. Hastalardan bilgilendirilmiş olur alınmıştır. Antalya Eğitim ve Araştırma Hastanesi etik kurulunda onay alınmıştır.

\section{BULGULAR}

Hastaların 35'i (\%57.4) erkek, 26'sı (\%42.6) kadındı. Hastaların yaş ortalaması 74.9 \pm 12.18 (40-102) yıldı. Hastaların 27'sine (\%44.3) demans, 19'una (\%31.1) serebrovasküler hastalık (SVO), 13'üne (\%21.3) malignite ve 2 'sine (\%3.3) amiyotrofik lateral skleroz (ALS) tanıları ile beslenme desteği verildiği kaydedildi. Hastaların demografik yapıları ve hastalık tanıları Tablo 1'de sunulmuştur. Takip zamanı sonunda 20 (\%32.8) hasta exitus oldu. Exitus olan hastaların tamamı NG sondayla besleniyordu. 13
(\%21.3) hasta NG sondayla beslenmeye devam ediyordu. 12 (\%19.7) hastaya PEG açıldı. 16 (\%26.3) hasta yeniden oral yolla beslenmeye başladı. Takip zamanı sonu NG sondayla beslenme durumları Tablo 2'de sunulmuştur. Hiçbir hastada NG sonda komplikasyonu görülmemiştir.

\section{TARTIŞMA}

Klinik pratikte enteral yoldan beslenmeye karar verilen hastalarda ne zaman PEG açılacağı konusunda kafa karışıklığı vardır. Açılacak olan PEG masum bir işlem olmayıp bir takım komplikasyonları vardır (4). Zaten tıbbi durumları hassas olan bu grup hastaları, olası PEG komplikasyonlarına maruz bırakmak, mortalite ve morbiditeye sebep olacak, tıbbi durumlarını daha da kötüleştirecektir. Ayrıca hastaların akut patolojileri iyileşince yeniden oral yolla beslenmeye başlamaları da olasıdır. Tüm bu durumlar göz önünde bulundurularak PEG açma kararı verilmelidir.

Çalışmamızda 12 (\%19.7) hastaya PEG açıldı. PEG açılan hasta sayısından fazla olarak da 16 (\%26.2) hastada oral yoldan beslenmeleri yeterli olduğu için yeniden oral beslenmeye geçildi. Beslenme kılavuzları 6 haftadan uzun süre enteral yoldan beslenmeye devam edilecek hastalara PEG açılmasını önermektedir (2,3). Ancak çalışmamızda

\begin{tabular}{|c|c|}
\hline \multicolumn{2}{|l|}{ Cinsiyet } \\
\hline Erkek, n (\%) & $35(57.4)$ \\
\hline Kadın, n (\%) & $26(42.6)$ \\
\hline Yaş (yıl), mean $\pm S D$ & $74.9 \pm 12.18(40-102)$ \\
\hline \multicolumn{2}{|l|}{ Primer hastalık } \\
\hline Demans, n (\%) & $27(44.3)$ \\
\hline SVO, n (\%) & $19(31.1)$ \\
\hline Malignite, n (\%) & $13(21.3)$ \\
\hline ALS, n (\%) & $2(3.3)$ \\
\hline
\end{tabular}

SVO: Serebrovasküler olay, ALS: Amiyotrofik lateral skleroz.

Tablo 2. Takip zamanı sonu hastaların NG sonda beslenme durumları

\begin{tabular}{|ll|}
\hline Exitus, $\mathrm{n}(\%)$ & $20(32.8)$ \\
\hline NG sonda ile beslenmesi sonlanan, $\mathrm{n}(\%)$ & $28(45.9)$ \\
\hline Oral beslenmeye geçen, $\mathrm{n}(\%)$ & $16(26.2)$ \\
\hline PEG açlan, $\mathrm{n}(\%)$ & $12(19.7)$ \\
\hline NG tüp ile beslenmeye devam eden, n (\%) & $13(21.3)$ \\
\hline Toplam, n (\%) & $61(100)$ \\
\hline
\end{tabular}

NG: Nazogastrik, PEG: Perkütan endoskopik gastrostomi. 
PEG açılan hasta sayısından daha fazla sayıda yeniden oral yolla beslenmeye geçilen hasta olması, hastalara hemen PEG açmak yerine, en azından akut patolojileri düzelene kadar ya da kronik patolojilerinin kliniği yerleşene kadar beklenmesi gerektiğini gösterdi diye düşünüyoruz. Bunun sağlanabilmesi için hastanelerin, bizim hastanemizde olduğu gibi, hastaların yutma fonksiyonlarını değerlendiren bir disfaji grubu ile koordinasyon içinde çalışan nütrisyon ekiplerinin olması gerekir diye düşünüyoruz.

NG sondayla beslenmenin özellikle aspirasyon ve buna bağlı pnömoni gibi ciddi riskleri göz önüne alındığında, hastaları NG sondayla taburcu edebilmek için hasta yakınlarına sıkı bir eğitim verilmesi ve hastaların taburculuk sonrası yakın takip edilmesi gerekir. Bizim çalışmamızda NG sondaya ait herhangi bir komplikasyon gelişmemiş olması hastaların yakın takip edilmesi ve hasta yakınlarının sıkı eğitilmesinden kaynaklandığını düşünüyoruz.

Exitus olan 20 (\%32.8) hastanın exitus olduğu anda NG sondayla besleniyor olmasının, hastaların enteral beslenmeye karar verildikten sonra neden NG sondayla bir geçiş süreci yaşaması gerektiğini gösterdiğini düşünüyoruz. Aynı zamanda bu hastalar NG sondayla taburcu edilerek olası PEG'e bağlı morbidite ve mortaliteden korunmuştur.

13 (\%21.3) hastanın NG sondayla beslenmeye devam edecek olmasının sebebi ise $6(\% 10)$ hasta ve/veya hasta yakınlarının PEG açılmasını kabul etmemesi ve 7 (\%11.3) hastanın çalışma zamanı dilimi sonunda takiplerinin devam ediyor olması olarak kaydedildi.

\section{KAYNAKLAR}

1. Mensforth A, Nightingake J. Insertion and care of enteral feding tubes. In: Nightingale JMD, (ed). Intestinal Failure. London: Greenwich Medical Media Ltd, 2001;281-303.

2. H Lochs, L Valentini, T Schütz, et al.Clinical Nutrition 2006;25:177360 .

3. NICE Clinical Guidelines, No.32. Nutrition support for adults; Oral nutrition support, enteral tube feding and parenteral nutrition. National Collaborating Centre for Acute Care (UK); 2006 Feb, ISBN10:0-9549760-2-9.

4. Koçak E, Filik L. Perkütan endoskopik gastrostomi. Endoskopi 2009;17:124-7.

5. Johnston SD, Tham TC, Mason M. Death after PEG: results of the National Confidential Enquiry into Patient Outcome and Death. Gastrointest Endosc 2008;68:223-7.

6. Norton B, Homer-Ward M, Donelly MT, et al. A randomised prospective comparison of percutaneous endoscpic gastrostomy and nasogastric tube feding afer acute dyspahgic stroke. BMJ 1996;312:13-6.
Çalışmamızı dizayn ederken literatürü taradığımızda, yapılmış olan çalışmaların, meta-analizlerin, derlemelerin belirli hasta gruplarında NG sondayla beslenme ve PEG ile beslenme yollarının birbirlerine olan üstünlüklerini ve/ veya herhangi birinin mortalite, morbidite ve beslenme durumunu gösteren parametrelere olan etkileri, yaşam kalitesi gibi değişkenlere olan etkilerini konu eden çalışmalar olduğunu gördük (5-10). Kendi çalışmamızla karşılaştırabileceğimiz şekilde dizayn edilmiş ve benzer amaçla yapılmış çalışmalar yoktu. Bu anlamda çalışmamı NG tüpten PEG ile beslenmeye geçme konusunda ne kadar aceleci olunması gerektiği konusunda klinisyenlere bir fikir vereceğini düşünüyoruz. Bu konuda tabi ki kılavuzların takip edilmesi çok önemli. Ancak PEG ile beslenmeye geçilmesi zamanlamasının hastaya göre bireyselleştirilmesi de uygun bir yaklaşım olacaktır. Dolayısıyla bu karar verilene kadar hastanın NG sondayla taburcu edilmesi uygun bir yaklaşım olacaktır.

Hasta sayısının az olması, takip sürecinin kısa olması, hastalıklara göre değerlendirme yapılmamış olması çalışmamızın negatif yönleri olarak karşımıza çıkıyor. Bu konuyla ilgili prospektif, kontrollü, kişilerin hastalık gruplarına göre gruplandırılarak yapılacak çalışmalar literatüre daha çok katkıda bulunacaktır.

Hastaların kalıcı beslenme yolu değişiklikleri kararı verilme sürecinde hastaları NG sondayla taburcu etmek uygun bir yaklaşım olacaktır. Beslenme yolu değişikliği kararının kılavuzlar eşliğinde hastaya göre bireyselleştirilmesi uygun bir yaklaşım olacaktır.
7. Dwolatzky T, Berezovski S, Friedmann R, et al. A prospective comparison of use of nasogastric and percutaneous endoscpic gastrostomy tubes for long-term enteral feedin in older people. Clin Nutr 2001;20:535-40.

8. Baeten C, Hoefnagels J. Feeding via nasogastric tube or percutaneous endoscpic gastrostomy. A comparison. Scand J Gastroenterol Suppl 1992;194:95-8.

9. Dennis M, Lewis S, Cranswick G, Forbes J; FOOD Trial Collaboration. FOOD a multicentre randomised trial evaluating feding policies in patients admitted to hospital with a recent stroke. Health Technol Assess 2006; 10:iii-iv, ix-x, 1-120.

10. Geenage C, Beavan J, Ellender S, Bath PM. Interventions for dysphagia and nutritional support in acute and subacute stroke. Cochrane Database Syst rev 2012;10:CD000323. 